\title{
Platelet Glycoproteins la, Ic, and Ila Are Physicochemically Indistinguishable from the Very Late Activation Antigens Adhesion-related Proteins of Lymphocytes and Other Cell Types
}

Ken D. Pischel, Harry G. Bluestein, and Virgil L. Woods, Jr. Division of Rheumatology, Department of Medicine, University of California Medical Center, San Diego, California 92103

\section{Abstract}

The very late activation antigens (VLA) are a subset of the superfamily of cell surface glycoproteins that serve as receptors from extracellular matrix proteins. One or more of the VLA heterodimers are present on T lymphocytes and most other cell types, including platelets. We have used VLA-specific monoclonal antibodies to isolate the reactive platelet membrane molecules. We have identified them as previously characterized platelet surface glycoproteins and have compared them with VLA molecules isolated from lymphocytes and other cells. Utilizing one-dimensional SDS-PAGE, twodimensional $O$ 'Farrell gel electrophoresis, and nonreduced-reduced two-dimensional gel electrophoresis, we show that reduced VLA molecules of platelets are composed of three chains of molecular weights $165,000,145,000$, and 140,000 that possess the physicochemical properties of platelet glycoproteins GPIa, GPIc $\alpha$, and GPIIa. GPIa corresponds to the VLA $165,000 \alpha^{2}$-chain, GPIIa corresponds to a $145,000 M_{r}$ VLA $\beta$-chain, and GPIc $\alpha$ corresponds to a 140,000 $M_{\mathrm{r}}$ VLA $\alpha$-chain.

The polypeptide structure of VLA molecules on platelets and lymphocytes are very similar or identical. Platelet proteins GPIa and GPIIa exist as a mixed heterodimer in detergent lysates and correspond with the VLA-2 heterodimer found on activated $\mathrm{T}$ lymphocytes and other cell types. The platelet glycoproteins GPIIa and GPIc form a second mixed heterodimer. The mAb A-1A5, which binds to the VLA $\beta$ chain, binds to platelet GPIIa and precipitates both the GPIIa-GPIa and GPIIa-GPIc heterodimers, and binds to $4,926 \pm 740$ sites per platelet. A VLA-2-specific mAb, 12F1, which binds to the VLA $\alpha^{2}$-chain reacts with GPIa and immunoprecipitates only the GPIIa-GPIa heterodimer, and binds to $1,842 \pm 449$ sites per platelet. The similarity of VLA chains and platelet GPIIa, GPIa, and GPIc molecules suggests that these molecules may have similar functions on various cell types.

\section{Introduction}

The very late activation antigens (VLA) ${ }^{1}$ are a set of human cell surface glycoproteins (1-5) that have been implicated as

Address reprint requests to Dr. Pischel.

Received for publication 2 September 1986 and in revised form 10 August 1987.

1. Abbreviations used in this paper: ACD, acid citrate dextrose; GP, platelet glycoproteins; NW, nylon wool; SAC, Staphylococcus aureus

J. Clin. Invest.

(c) The American Society for Clinical Investigation, Inc.

0021-9738/88/02/0505/09 \$2.00

Volume 81, February 1988, 505-513 receptors for extracellular matrix proteins $(6,7)$. They were initially named "very late activation antigens" because after long-term $\mathrm{T}$ cell activation, the $\beta$-chain increases in amount and additional $\alpha$-subunits appear. More specifically, T cells in the resting state express a $130,000-M_{\mathrm{r}}$ chain that is recognized by the mAb A-1A5 and is termed the $\beta$-chain (4). With long term mitogen- or mixed lymphocyte reaction (MLR)-activation, VLA increases in amount and the $\beta$-chain forms noncovalently linked heterodimers with either a $200,000-M_{\mathrm{r}}\left(\alpha^{1}\right)$ or a $165,000-M_{\mathrm{r}}\left(\alpha^{2}\right)$ glycoprotein. The $\alpha^{1} \beta$ complex is termed VLA-1 and the $\alpha^{2} \beta$ complex is termed VLA-2. Studies of the cellular distribution of VLA molecules show that the common $130,000-M_{\mathrm{r}} \beta$ chain is present upon many types of resting and activated cells. Resting platelets also express VLA-like glycoproteins with 140,000 - and $165,000-M_{\mathrm{r}}$ chains that can be immunoprecipitated by VLA-specific monoclonal antibodies $(2,8)$. The VLA family includes at least three more heterodimers, VLA-3, VLA-4, and VLA-5 (5). The VLA-3 and VLA-5 heterodimers have been recently found to be similar or identical to receptors for fibronectin and laminin (6).

Platelet surface proteins have been identified and analyzed by a variety of physicochemical techniques, including O'Farrell isoelectric-focusing SDS-PAGE two-dimensional (2D) gel analysis (9-11), and nonreduced-reduced 2D diagonal SDSPAGE $(10,12,13)$. In this study we have isolated VLA from platelets by immunoprecipitation with VLA-specific mAbs and used these techniques to identify the immunoprecipitated molecules. These experiments show that these platelet molecules are composed of three proteins previously characterized as platelet glycoproteins GPIa, GPIc, and GPIIa and provide evidence that in detergent solution there exists mixed heterodimers of GPIIa with GPIa, and GPIIa with GPIc. Those platelet glycoproteins share physicochemical properties with lymphocyte VLA-2 and VLA-3. GPIIa is homologous to the VLA $\beta$-chain, GPIa to the VLA $\alpha^{2}$-chain and GPIc to a different VLA $\alpha$ chain.

\section{Methods}

Cell preparation. Peripheral blood mononuclear cells (PBMs) were obtained by Ficoll-Hypaque (Pharmacia Fine Chemicals, Piscataway, $\mathrm{NJ}$ ) density gradient centrifugation (14) and washed three times with RPMI 1640. These were further processed by passage through a nylon wool (NW) column (15) to yield NW T-enriched cells ( $\mathrm{T}$ cells) before iodination. The T cell leukemia Mo-1 (16) was obtained from the American Type Culture Collection (Rockville, MD; ATCC, CRL 8066) and passaged in Iscove's Modified Dulbecco's Media supplemented with $10 \%$ fetal calf serum (FCS). The neuroblastoma cell line SK-N-SH was obtained and cultured as previously described $(17,18)$.

Platelet preparations. $30 \mathrm{ml}$ of venous blood was obtained from aspirin-free healthy individuals and mixed with $5 \mathrm{ml}$ acid-citrate dex-

Cowan's strain I; 2D, two-dimensional; TBS, Tris-buffered saline; 2-ME, 2-mercaptoethanol; VLA, very late activation antigen. 
trose (13.5 g citric acid, $25 \mathrm{~g} \mathrm{Na}$ citrate, $20 \mathrm{~g}$ dextrose per liter, $\mathrm{pH} 4.5$, $\mathrm{ACD}$ ) and centrifuged at $180 \mathrm{~g}$ for $15 \mathrm{~min}$ at $22^{\circ} \mathrm{C}$ to yield platelet-rich plasma (19). The platelets were then washed twice by suspension and

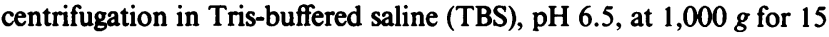
min and then iodinated.

Radiolabeling. Lymphocytes were surface iodinated by a modification of the method of Baur et al. (20). To $5 \times 10^{7}$ cells in $500 \mu \mathrm{l}$ PBS were added $1 \mathrm{mCi} \mathrm{Na}^{125} \mathrm{I}$ (New England Nuclear, North Billerica, MA) and $10 \mu \mathrm{l}$ lactoperoxidase (Calbiochem-Behring Corp., San Diego, CA; B grade, $100 \mathrm{IU} / \mathrm{ml}$ ) and $25 \mu \mathrm{l}$ of $0.03 \% \mathrm{H}_{2} \mathrm{O}_{2}$. After $5 \mathrm{~min} 5 \mu \mathrm{l}$ of lactoperoxidase and $10 \mu \mathrm{l}$ of $0.03 \% \mathrm{H}_{2} \mathrm{O}_{2}$ was added and at $10 \mathrm{~min} 10$ $\mu \mathrm{l}$ of $0.03 \% \mathrm{H}_{2} \mathrm{O}_{2}$ was added. After $15 \mathrm{~min}$ the reaction was stopped by the addition of cold RPMI and cells washed six times with media. Viability was $>95 \%$ before and following iodination as judged by trypan blue exclusion. Platelets $\left(1 \times 10^{8}\right)$ were suspended in $500 \mu \mathrm{l} \mathrm{TBS}$ (pH 7.4) containing $1 \mathrm{mCi} \mathrm{Na}^{125} \mathrm{I}$ to which lactoperoxidase and $\mathrm{H}_{2} \mathrm{O}_{2}$ were added as above. Platelets were washed four times after iodination with TBS pH 6.5.

Antibodies. The anti-VLA monoclonals A-1A5 and TS2/7 $(1,2)$ were the generous gift of Dr. Martin Hemler (The Dana-Farber Cancer Institute, Harvard Medical School, Boston, MA). AN51 mAb to GPIb (21) was purchased (Dako, Santa Barbara, CA). S1 2 mAb to GMP-140 (22) was the generous gift of Dr. McEver and Dr. Martin (University of Texas Health Service Center, San Antonio, TX). The mAb 2G12, which recognizes an epitope of platelet GPIIb/GPIIIa complex (19), and $\mathrm{mAb} 12 \mathrm{~F} 1$ which recognizes VLA-2 (8) were produced by us. The VLA-2 specificity of $12 \mathrm{~F} 1$ appears to be due to its reaction with determinants on the $\alpha^{2}$-chain.

Extraction and immunoprecipitation. Cells were lysed with nonionic detergent and immunoprecipitated as previously described $(8$, $23,24)$. Platelets were suspended in $1.5 \mathrm{ml}$ TBS pH 7.4 to which $1.5 \mathrm{ml}$ of TBS containing $2 \times 10^{-5} \mathrm{M}$ leupeptin (Sigma Chemical Co., St. Louis, MO), 2 mM PMSF, 2\% Triton-X 100 was added. Lymphocytes and neuronal cells were lysed in $0.15 \mathrm{M} \mathrm{NaCl}, 0.01 \mathrm{M}$ Tris $\mathrm{pH} 7.4$, $0.5 \%$ NP-40 (TBS-NP-40) containing $0.06 \mathrm{mM} N$ - $\alpha$-p-tosyl-L-lysine choromethyl ketone (TLCK), $0.06 \mathrm{mM}$ L-1-methyl ketone (TPCK) and $0.2 \mathrm{mM}$ phenylmethylsulfonyl-fluoride (PMSF; all from Sigma Chemical Co., St. Louis, MO) for $30 \mathrm{~min}$ at $4^{\circ} \mathrm{C}$. After incubation for $30 \mathrm{~min}$ at $4^{\circ} \mathrm{C}$ cellular and platelet lysates were ultracentrifuged at $100,000 \mathrm{~g}$ for $30 \mathrm{~min}$ at $4^{\circ} \mathrm{C}$ and used immediately or frozen at $-70^{\circ} \mathrm{C}$ until used. Aliquots were precleared by incubation with $100 \mu \mathrm{l}$ of $10 \%$ Sansorbin (Staphylococcus aureus lacking protein A; CalbiochemBehring Corp.) for $15 \mathrm{~min}$ followed by centrifugation (microfuge B; Beckman Instrument Co., Inc., Palo Alto, CA) for $4 \mathrm{~min}$.

Antibodies were added to the detergent-solubilized lysates after preclearance and incubated for $30 \mathrm{~min}$ at $4^{\circ} \mathrm{C}$. The specific immune complexes were collected with $50 \mu \mathrm{l}$ of $10 \% \mathrm{~S}$. aureus Cowan's strain I (SAC) (Calbiochem-Behring Corp.) or protein A conjugated to Sepharose $4 B$ or with $10 \mu \mathrm{l}$ of affinity purified rabbit anti-mouse kappa chain conjugated to Sepharose 4B $(1 \mathrm{mg} / \mathrm{ml})$ as per the manufacturer's instructions (Pharmacia Fine Chemicals), and washed six times with TBS-NP-40. Washed pellets were eluted and denatured with $50 \mu \mathrm{l} 1 \%$ SDS and 5\% 2-mercaptoethanol (2-ME) by heating at $100^{\circ} \mathrm{C}$ for $1-2$ min and analyzed by $8 \%$ Laemmli SDS-PAGE $(25)$ along with ${ }^{14} \mathrm{C}$ molecular weight markers myosin $\left(200,000 M_{\mathrm{r}}\right)$, phosphorylase B $\left(92,000 M_{\mathrm{r}}\right)$, BSA $\left(68,000 M_{\mathrm{r}}\right)$, ovalbumin $\left(45,000 M_{\mathrm{r}}\right)$, chymotrypsin $\left(25,000 M_{\mathrm{r}}\right)$, beta-lactoglobulin $\left(18,400 M_{\mathrm{r}}\right)$, and cytochrome $c(12,400$ $M_{\mathrm{r}}$ ) (Bethesda Research Laboratories, Gaithersburg, MD), then dried and autoradiographed.

Platelet radioligand-binding studies. Platelet-rich plasma was prepared from ACD-collected whole blood, and platelets were pelleted and then gel filtered on Sepharose CL-2B at room temperature in divalent cation-free Tyrode's buffer, $\mathrm{pH} 7.2$, containing $2 \%$ bovine serum albumin and $0.1 \%$ glucose (TBG) as previously described (26). They were then reacted $\left(1 \times 10^{7}\right.$ platelets $/ \mathrm{ml} 1 \mathrm{mM} \mathrm{CaCl}_{2}, 1 \mu \mathrm{M}$ $\mathrm{PGE}_{1}$ ) for $60 \mathrm{~min}$ with dilutions of chloramine-T radioiodinated DEAE-cellulose purified monoclonals A-1 A5 or $12 \mathrm{~F} 1\left(3.33 \times 10^{11}-1\right.$ $\left.\times 10^{-8} \mathrm{M}\right)$. Cell-bound ligand was separated from free ligand by cen- trifugation of platelets through $20 \%$ sucrose in TBG and measured as previously described (26). Ligand binding was assessed, and results were analyzed by the method of Scatchard (27). Nonspecific binding was determined by performing binding studies in the presence of a $50-100$-fold excess of unlabeled ligand and was found to be $<5 \%$ of total binding. The line that best fits the data was generated by least squares linear regression.

Sequential nonreduced-reduced SDS-PAGE. Immunoprecipitates were prepared and processed as described above except they were not reduced and one-dimensional electrophoresed using $6 \%$ or $8 \%$ SDSPAGE tube gels. After electrophoresis in the first dimension the tube gels were equilibrated with SDS-PAGE loading buffer containing $5 \%$ 2-mercaptoethanol (2-ME) for $15 \mathrm{~min}$ at $22^{\circ} \mathrm{C}$ and then run in the second dimension on a $8 \%$ slab SDS-PAGE, processed, and autoradiographed as described above for one-dimensional SDS-PAGE.

$O$ 'Farrell $2 D-P A G E$. 2D-PAGE was carried out after the method of O'Farrell $(28)$ as previously described $(8,23)$. Samples were eluted from the SAC or Sepharose immunoadsorbents by incubation with 8 $\mathrm{M}$ urea, 5\% 2-ME for $60 \mathrm{~min}$ at $22^{\circ} \mathrm{C}$ and applied to prefocused $6 \%$ acrylamide tube gels with $10 \mathrm{mM}$ phosphoric acid and $50 \mathrm{mM}$ Tris electrode solutions, and focused for $10 \mathrm{~h}$ at $1,000 \mathrm{~V}$. The gels were then equilibrated with SDS-PAGE diluent buffer and run on $8 \%$ SDSPAGE in the second dimension and processed as described above for 1D SDS-PAGE.

Neuraminidase digestion. Neuraminidase (isolated from Clostridia perfringens, Sigma Chemical Co.) was added to iodinated lysates at $0.08 \mathrm{U} / \mathrm{ml}$ and incubated at $37^{\circ} \mathrm{C}$ for $60 \mathrm{~min}$ and then immunoprecipitates prepared.

\section{Results}

One-dimensional SDS-PAGE of platelet molecules precipitated with VLA-specific MAbs reveals multiple chains. The VLAspecific mAb A-1A5 was used to immunoprecipitate nonionic detergent extracts of lactoperoxidase cell surface iodinated platelets, SK-N-SH neuronal cells and the T cell leukemia line Mo-1 and immunoprecipitated molecules analyzed by SDSPAGE (Fig. 1). The SK-N-SH (lane 1 ) and leukemic T cell line Mo-1 (lane 2) preparations contained the three bands of $180,000 M_{\mathrm{r}}\left(\alpha^{1}\right), 160,000 M_{\mathrm{r}}\left(\alpha^{2}\right)$ and $130,000 M_{\mathrm{r}}(\beta)$ chains, which are characteristic of a mixture of VLA-1 ( $\alpha^{1} \beta$ heterodimer) and VLA-2 ( $\alpha^{2} \beta$ heterodimer) as previously described (4, 23). The platelet A-1A5 precipitate (lane 3 ) contained two bands of $165,000 M_{\mathrm{r}}$ and $145,000 M_{\mathrm{r}}$ that were of nearly equal radioactive intensity. Similar results have been obtained with platelets from 20 different donors. These chains were of slightly greater molecular weight than the VLA $\alpha^{2}$ and $\beta$ chains isolated from the T cell line. Previous small differences of VLA have been observed that disappear on removal of the carbohydrate (4). Platelets lack the $180,000 M_{\mathrm{r}}$ VLA $\alpha^{1}$ chain. Thus, it appears that the platelet VLA-2 heterodimers comprise a large fraction of the platelet VLA molecules.

The similar one-dimensional SDS-PAGE pattern of the monoclonal antibody precipitated VLA from platelets and other cell types led us to compare immunoprecipitated samples from lymphoid and platelet sources by O'Farrell 2D gel electrophoresis (Fig. 2). Samples of VLA prepared with $\mathrm{mAb}$ A-1 A5 from platelets and CEM were analyzed individually $(A$, and $C$ ) and simultaneously $(B)$. The platelet samples included two dark spots of $165,000 M_{\mathrm{r}}(\mathrm{pI} 5.5)$ and $145,000 M_{\mathrm{r}}(\mathrm{pI}$ 5.0-5.5) and a third less intense spot of $140,000 M_{\mathrm{r}}$ (pI 5.5). The CEM samples included spots focusing at positions indistinguishable from the two prominent platelet proteins both separately and when a mixture was analyzed $(C)$. Since a small 


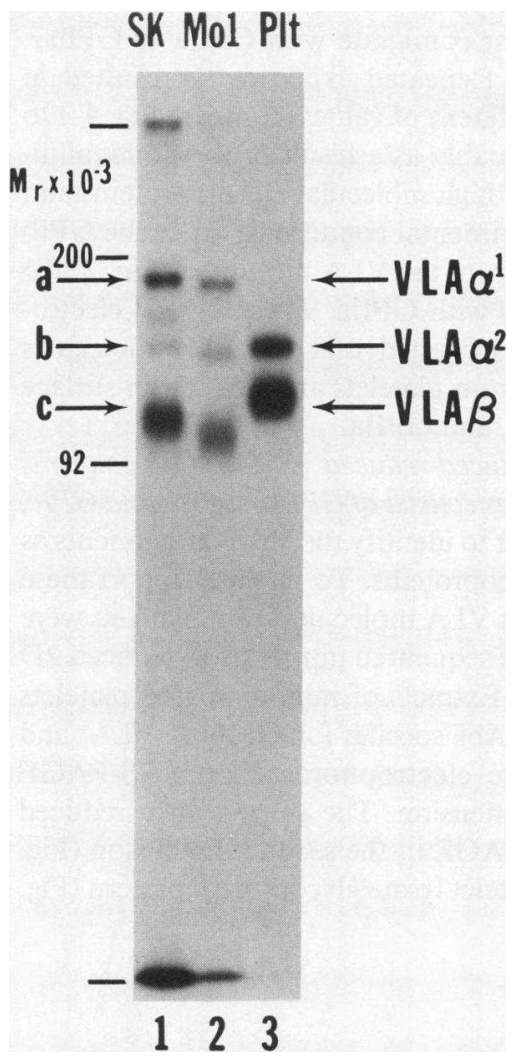

Figure 1. Immunoprecipitation of VLA molecules from platelets, a T cell line, and neuronal cell line with the antiVLA specific $\mathrm{mAb}$ A-1A5. NP-40 detergent lysates of lactoperoxidase ${ }^{125}$ I radiolabeled SK-N-SH neuronal cells (lane 1 ), $\mathrm{T}$ leukemia cell line Mo-1 (lane 2) and platelets (lane 3) were incubated with the VLA specific mAb A-1A5 and immune complexes collected with $70 \mu \mathrm{l}$ $10 \%$ SAC as described in Methods. Immunoprecipitates were eluted and reduced with $2 \%$ SDS-5\% 2-ME, run on $8 \%$ SDS-PAGE and autoradiographed. Molecular weight markers are shown at left. The SK-N-SH VLA chains labeled (a) corresponds with the $180,000 \mathrm{~mol}$ wt $\alpha^{1}$ chain, (b) to the $160,000 \mathrm{~mol} \mathrm{wt} \alpha^{2}$ chain, and $(c)$ to the 130,000 mol wt $\beta$-chain.

difference might not be detected due to the broadness of the darkest band, a pattern often caused by various numbers of sialic acid residues, samples were prepared and compared from neuraminidase-treated lysates of platelets and CEM cells $(D-F)$. The patterns of both the most intense-platelet spot $(D)$ and CEM spot corresponding to the VLA chain $(D)$ became sharper and focused at $\mathrm{pH} 5.5$ after removal of sialic acid. Again their migration on 2D electrophoresis were indistinguishable from one another. Comparison of the platelet 2D pattern with published patterns of VLA family members $(5,8$, 23) identifies these VLA components as migrating with patterns characteristic of the VLA $\beta$ chain, VLA $\alpha^{2}$ chain, and VLA $\alpha^{3}$ or VLA $\alpha^{5}$ chain.

VLA molecules are distinct from GPIIb/IIIa, GMP140, and GPIb. We sought to determine which of the previously physicochemically characterized platelet membrane glycoproteins comprise the anti-VLA immunoprecipitates. The electrophoretic mobilities of platelet VLA molecules were compared with those of platelet GPIIb and GPIIIa, GP140, and GPIb in nonreduced conditions (Fig. 3) and reduced conditions (not shown). Aliquots of nonionic detergent lysates of radioiodinated platelets were immunoprecipitated with A-1A5, 12F1, GPIb-specific AN51, GP140-specific S12, and GPIIb/IIIa-specific $\mathrm{mAb} 2 \mathrm{G} 12$, and the precipitates were examined without 2-ME reduction on ID SDS-PAGE. GPIIb and GPIIIa demonstrated their characteristic migration patterns (13). The VLA chains from platelets (lanes 2 and 3 ) were clearly different from those of GPIIb and GPIIIa (lane 5). The strong radioactive intensities of the immunoprecipitated VLA molecules suggested that the platelet VLA molecules are prominent radioiodinated species in platelet lysates. The GMP-140 specific
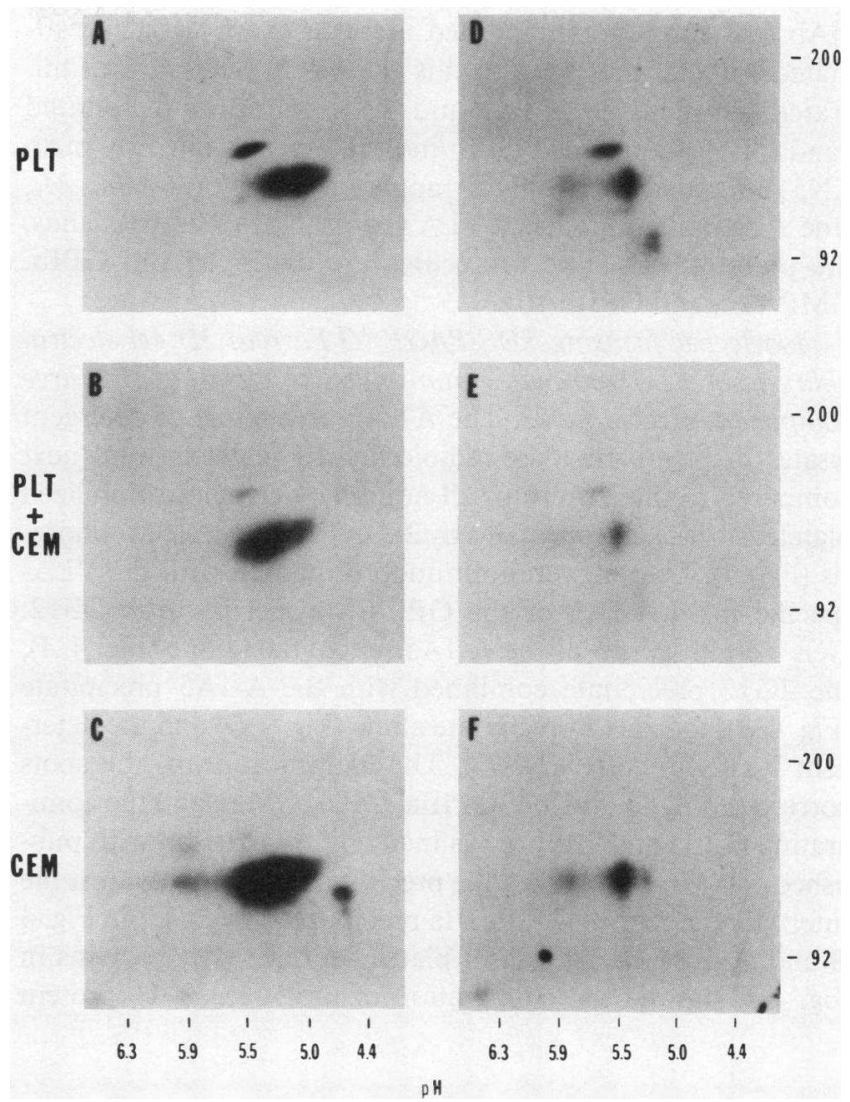

Figure 2. Comparison of VLA from platelets and lymphoid cell line CEM by O'Farrell 2D gel electrophoresis. Labeled extracts from platelets and CEM cells were divided and immunoprecipitated directly $(A-C)$ or following neuraminidase treatment $(0.08 \mathrm{U} / \mathrm{ml} 60$ min, $\left.37^{\circ} \mathrm{C}\right)(D-F)$. A-1 A5 immunoprecipitates from platelets $(A, D)$, CEM $(C, F)$ and mixture of platelet and CEM immunoprecipitates $(B, E)$ were reduced isoelectrically focused and then run on $8 \%$ PAGE.

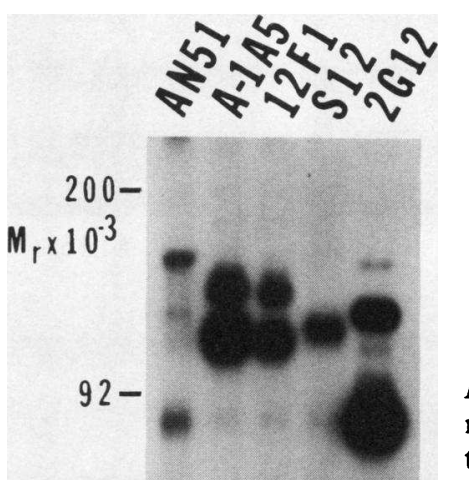

Figure 3. Comparison of the nonreduced SDS-PAGE patterns of VLA, GPIIb-IIIa, GPIb, and GMP-140. NP-40 lysates from ${ }^{125}$ I radioiodinated platelets were incubated with VLA specific mAbs A-1A5 (lanes 2 and 3), GPIb-specific mAb AN51 (lane 1) GMP-140 specific $\mathrm{mAb}$ S12 (lane 4) and GPIIb-GPIIIa specific mAb 2G12 (lane 5) and immune complexes collected. Samples were denatured under nonreducing conditions, run on $8 \%$ SDS-PAGE, and autoradio123455 graphed. 
mAb S12 immunoprecipitated a single chain with an estimated 150,000 mol wt with this gel system (lane 4) that migrated between the A-1A5 and 12F1 immunoprecipitated bands. The nonreduced GPIb molecule precipitated by mAb AN51 migrated with a higher apparent mol wt $\left(180,000 M_{\mathrm{r}}\right.$, lane 1 ) than the unreduced VLA chains (lanes 2 and 3). Thus, the platelet VLA-like molecules are distinct from GPIb, GMP-140, and GPIIb/IIIa.

Isoelectric focusing-SDS-PAGE (O'Farrell) $2 D$ gel electrophoresis of VLA molecules from platelets identifies the three component glycoproteins. The A-1A5 precipitate of detergent lysates of lactoperoxidase-radioiodinated platelets were next compared to the pattern of all nonionic detergent solubilized platelet surface glycoproteins by 2D O'Farrell gel electrophoresis (Fig. 4). Lysates were immunoprecipitated with the VLAspecific mAb A-1A5 or the GPIIb/IIIa-specific mAb 2 G12. Gels were then run of the A-1A5 precipitate alone (Fig. $4 \mathrm{~A}$ ), the $2 \mathrm{G} 12$ precipitate combined with the A-1A5 precipitate (Fig. $4 \mathrm{~B}$ ), the $2 \mathrm{Gl} 2$ precipitate alone (Fig. $4 \mathrm{D}$ ) and the detergent lysate alone (Fig. $4 E$ ). The identification of the spots corresponding to GPIIb $\alpha$, GPIII, GPIa, GPIc $\alpha$ and the comigrating GPIIa and GPIb $\alpha$ was made by comparison with published gels (8). Comparing the precipitate of A-1A5 against the internal reference of GPIIb/IIIa precipitated by $2 \mathrm{G} 12$ in Fig. 4 $B$ and against the pattern of platelet surface glycoproteins in Fig. $4 E$ showed the comigration of the $165,000 M_{\mathrm{r}}$ protein seen in the 1D SDS-PAGE with GPIa. Further, the $145,000 M_{\mathrm{r}}$ band seen in 1D SDS-PAGE is seen to resolve into two spots of slightly differing sizes and pIs $\left(145,000 M_{\mathrm{r}}, \mathrm{pI}=4.7\right.$ versus $140,000 M_{\mathrm{r}}, \mathrm{pI}=5.1$ ) that comigrate with GPIIa or GPIb $\alpha$, and GPIc $\alpha$, respectively. Repeated experiments resulted in similar, though slightly different pI values (compare Fig. $4 \mathrm{~A}$ to Figs. $2 A$ and $6 A$ ) presumably as a result of the nonequilibrium nature of focusing of high molecular weight proteins and minor differences in experimental conditions. Since the GPIb was shown to be distinct from the VLA molecules (Fig. 2) the data indicates it coincides with GPIIa. These 2D gel electrophoresis results strongly suggested that the VLA molecules precipitated with A-1A5 from platelets are the platelet surface glycoproteins GPIa, GPIc, and GPIIa.

Sequential 2D nonreduced-reduced SDS-PAGE confirms that platelet VLA molecules consist of GPIIa, GPIa, and GPIc. The results of Fig. 4 appear to identify the VLA components as major platelet surface glycoproteins. To further support these identifications, the platelet VLA molecules from platelets were analyzed by the method of sequential nonreduced-reduced 2D SDS-PAGE $(10,12,13)$. Extracts of radioiodinated platelets were precipitated with mAbs specific for GPIb or VLA, and immunoprecipitates were electrophoresed on SDS-PAGE unreduced in the first dimension. The gel was then reduced and resubjected to SDS-PAGE in the second dimension (Fig. 5). Comparison of the platelet lysate glycoprotein pattern (Fig.
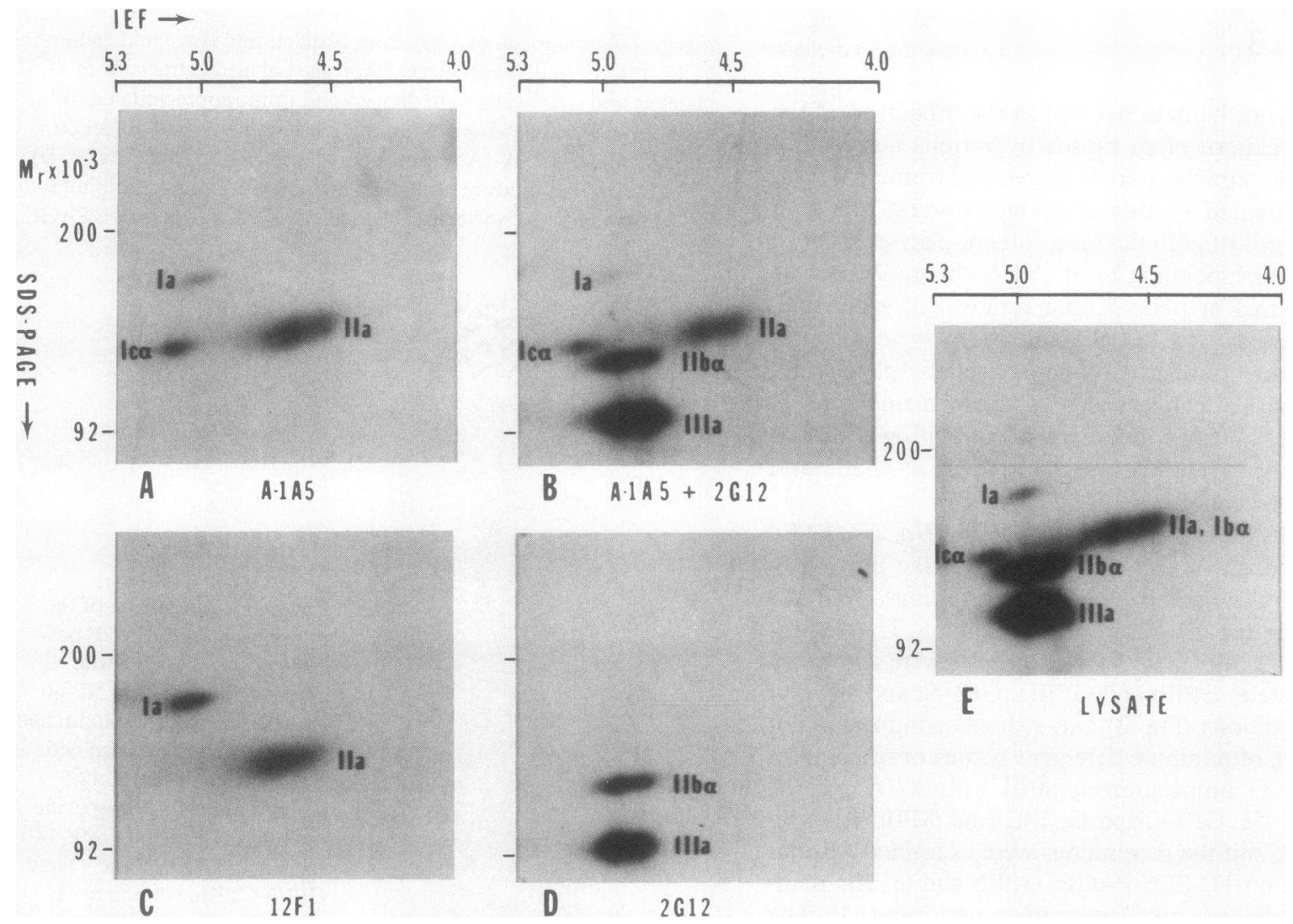

first dimension followed by $8 \%$ SDS-PAGE in the second dimension.

Figure 4. Isoelectric focusing SDS-PAGE 2D gel electrophoresis of platelet VLA molecules. Lysates from ${ }^{125} \mathrm{I}$ labeled platelets were immunoprecipitated with GPIIb/GPIIIa specific mAb 2G12 and VLA specific mAbs A-1A5 and 12F1. Individual immunoprecipitates and mixtures were reduced and subjected to isoelectric focusing in the

Samples were immunoprecipitated with $(A)$ A-1A5 (B) A-1A5 and $2 \mathrm{G} 12$ (mixture), $(C) 12 \mathrm{~F} 1,(D) 2 \mathrm{G} 12$. A sample of entire platelet lysate provided reference positions $(E)$. 


\section{NONREDUCE D}

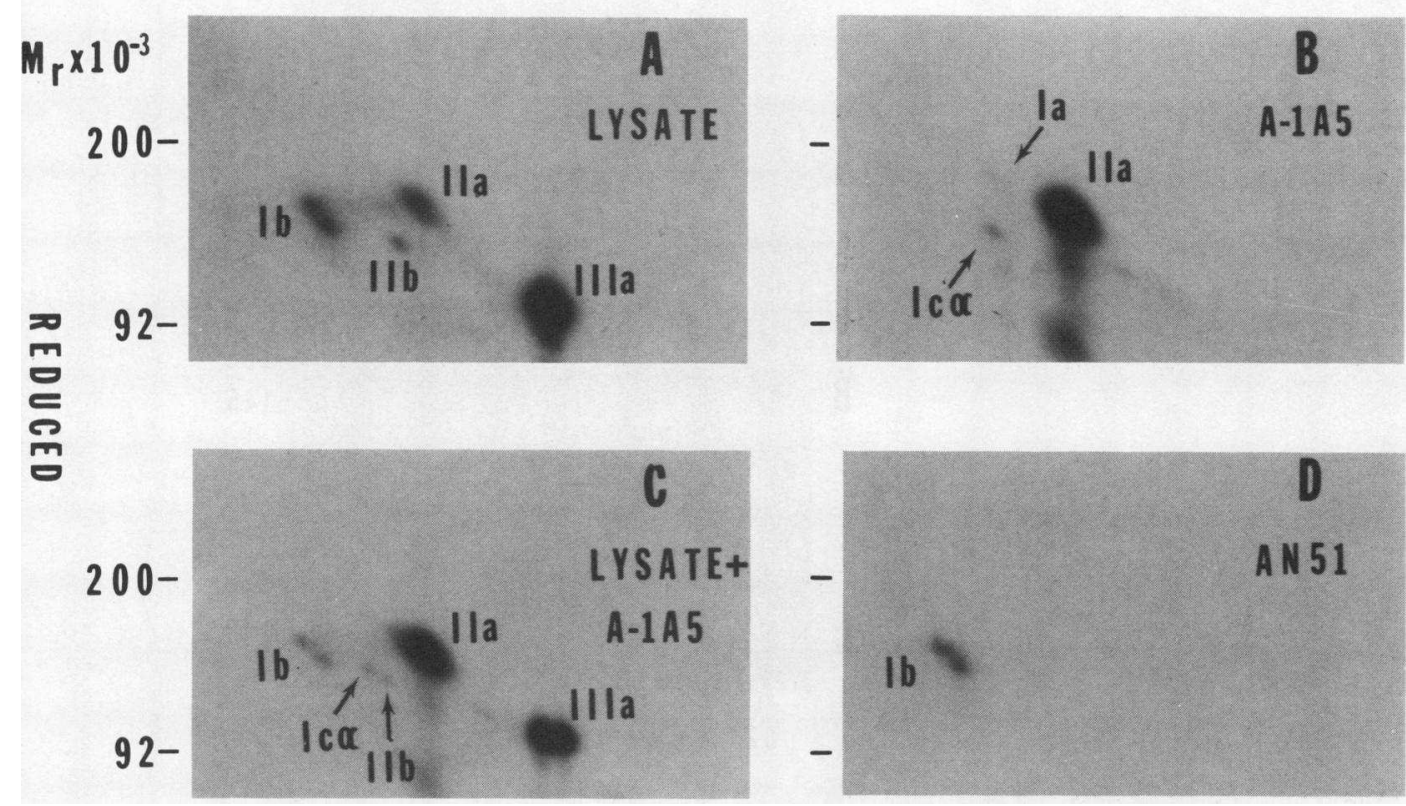

Figure 5. Nonreduced-reduced 2D gel electrophoretic comparison of platelet VLA and GPIIa. Immunoprecipitates from ${ }^{125}$ I-labeled platelet lysates were prepared with VLA specific MAb A-1A5 and GPIb specific mAb AN51. Immunoprecipitates were denatured in SDS (without reduction) and subjected to SDS-PAGE in the first dimension followed by reduction with 5\% 2 ME and SDS-PAGE (8\%) in the second dimension. Samples contained: $(A)$ platelet lysate, $(B)$ A-1A5 immunoprecipitated VLA, (C) A-1A5 immunoprecipitated VLA plus platelet lysate, (D) AN51 immunoprecipitated GPIb. Immunoprecipitated GPIIb, GPIIa, and GPIb, and the characteristic electrophoretic positions of ${ }^{125}$ I-labeled platelet glycoproteins $(9,10)$ were used to identify the major platelet glycoproteins (labeled).
$5 \mathrm{~A}$ ) with published patterns (12) allowed the identification of the positions of GPIb $\alpha$, GPIIa, GPIIb $\alpha$, and GPIIIa. GPIc $\alpha$ and GPIa were not detected in the lysate in this experiment possibly due to applying an insufficient amount of poor transfer of the molecules into the second dimension. The A-1A5 VLA precipitate consisted of three components (Fig. 5 $B$ ), a prominent $145,000 M_{\mathrm{r}}$ component that comigrated with GPIIa, and less intense $140,000-$ and $165,000-M_{\mathrm{r}}$ molecules. The $165,000-M_{\mathrm{r}}$ VLA molecule migrated in a position characteristic of GPIa. All three VLA components migrated to positions clearly distinct from the position of GPIb (Fig. $5 \mathrm{D}$ ). The addition of the A-1A5 VLA precipitate to the lysate (Fig. $5 C$ ) resulted in the appearance of a band just to the left of GPIIb $\alpha$ in a position characteristic of GPIc $\alpha$. These findings provide further evidence the VLA-homologous molecules of platelets are composed of the three glycoproteins GPIIa, GPIa, and GPIc.

$V L A-2$ specific monoclonal Ab $12 F 1$ precipitates platelet GPIa and GPIIa but not GPIc. The VLA $\beta$-chain forms heterodimers with several different $\alpha$ chains, including the $\alpha^{2}$-chain of VLA-2 recognized by mAb $12 F 1(4,5,8)$. Since one of the VLA reactive molecules on platelets, GPIIa, has the physicochemical properties of VLA $\beta$ chain, we used $\beta$-chain specific $\mathrm{mAb} A-1 \mathrm{~A} 5$, and $\alpha^{2}$-chain reactive mAb $12 \mathrm{~F} 1$ to analyze interchain relationships among platelet VLA-like glycoproteins. Detergent extracts of surface radioiodinated platelets were immunoprecipitated with $\mathrm{mAb} 12 \mathrm{~F} 1$ and precipitates analyzed by O'Farrell 2D gel electrophoresis (Fig. $4 C$ ). Unlike the A-1A5 immunoprecipitate, the $12 \mathrm{~F} 1$ immunoprecipitate (Fig. $4 C$ ) did not contain the GPIc $\alpha$ molecules. Similar results were obtained with A-1 A5, 12F1, and GPIIb-GPIIIa immunopre- cipitates analyzed by sequential nonreduced-reduced gel electrophoresis (data not shown). The most likely explanation for the findings is that A-1A5 reacts with GPIIa and Ia and Ic are coprecipitated because of a physical association with IIa, exactly analogous to the observations that A-1A5 precipitates various VLA $\alpha$-chains linked to the VLA- $\beta$ chain on other cell types. Since $12 \mathrm{~F} 1$ only immunoprecipitates Ia and IIa, the most likely interpretation is that the three platelet molecules precipitated by A-1A5 do not exist as a trimer. We suggest that like VLA on activated $T$ cells and other cells these platelet molecules exist as two types of heterodimers. The first, a complex of GPIIa with GPIa has been directly shown by immunoprecipitation and corresponds to the lymphocyte VLA-2 heterodimer composed of the common VLA $\beta$-chain with the VLA $\alpha^{2}$-chain. The second platelet heterodimer is suggested to be composed of GPIIa and GPIc. In order to obtain evidence of the second heterodimer, sequential immunoprecipitations were done (Fig. 6). Samples were first precleared with control mAb (lanes, 1, 5), A-1 A5 (lanes 2-4) or 12F1 (lanes 6-8) and then aliquots immunoprecipitated with $\mathrm{A}-1 \mathrm{~A} 5,12 \mathrm{~F} 1$, or $2 \mathrm{G} 12$. As expected the preclearance with A-1A5 resulted in removal of subsequent A-1A5 (lane 2) and 12F1 (lane 3) reactivity. Preclearance with $12 \mathrm{~F} 1$ was also complete (lane 7 ). The A-1A5 immunoprecipitate of the 12F1-precleared lysate contained only the $140,000 M_{\mathrm{r}}$ band(s) and no longer contained the $165,000 M_{\mathrm{r}}$ chain (lane 6). Two dimensional gel analysis of the immunoprecipitates from platelet lysates by A-1A5 $(A)$, $12 \mathrm{~F} 1(B)$, and A-1A5 after preclearance by $12 \mathrm{~F} 1(C)$ showed the latter retained both the $140,000-M_{\mathrm{r}}$ GPIc $\alpha$ and the $145,000-M_{\mathrm{r}}$ GPIIa. This result provides a direct demonstration of a heterodimer composed of GPIIa and GPIc. 


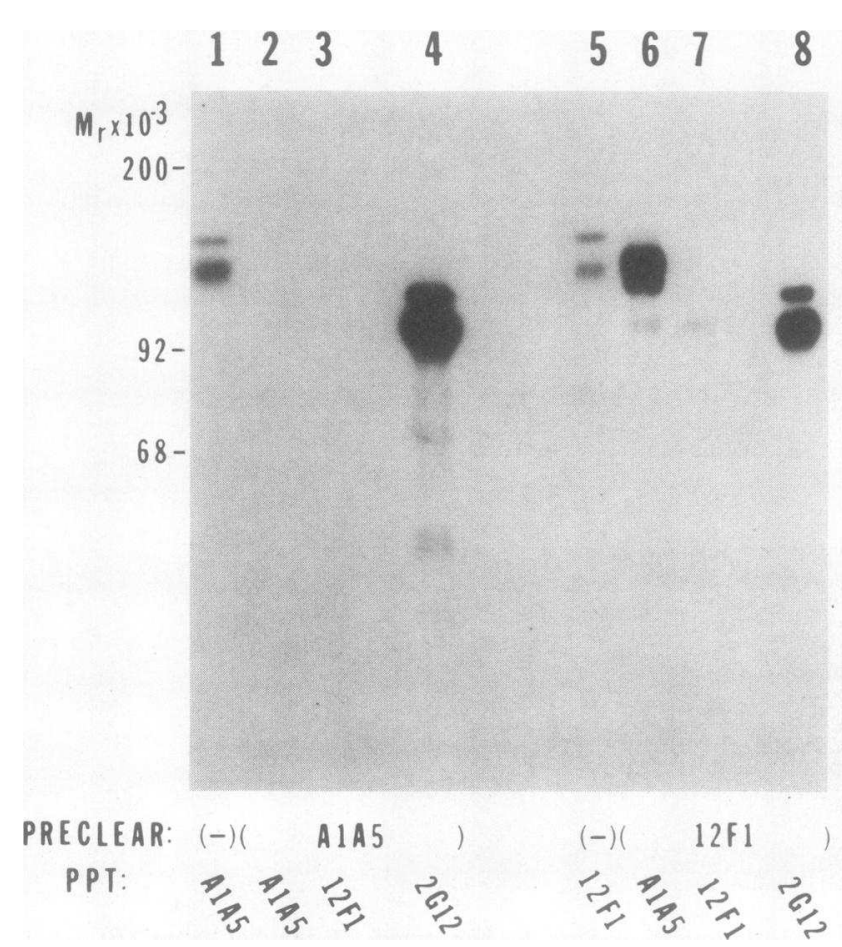

Figure 6. Sequential immunoprecipitation of platelet GPIIa, GPIa and GPIc molecules with mAbs $12 \mathrm{~F} 1$ and A-1A5 and demonstration of heterodimers by two-dimensional gel analysis. Lysates of 125 I-labeled platelets were precleared with control $\mathrm{mAb}$ (lanes 1 and 5), A-1A5 (lanes 2-4), and 12F1 (lanes 6-8). Following preclearance aliquots were immunoprecipitated with A-1A5 (lanes 1, 2, 6), 12F1

Quantitation of GPIIa and GPIa molecules on resting platelets. Radioligand binding studies using the mAb A-1A5 and $12 \mathrm{~F} 1$ were performed to quantitate the number of antibody reactive molecules of GPIIa and GPIa, respectively, on resting platelets. Gel-filtered platelets from four normal male donors were incubated at room temperature for $60 \mathrm{~min}$ with varying concentrations of radioiodinated A-1A5 or $12 \mathrm{~F} 1$. Platelets were then pelleted by centrifugation through $20 \%$ sucrose-TBG and ligand binding assessed (see Methods). A representative experiment is shown in Fig. 7. Platelets were found to have $4,926 \pm 740$ (mean $\pm \mathrm{SD})$ binding sites for A-1A5 $\left(K_{d}\right.$ $\left.=4.5 \pm 0.6 \times 10^{-10} \mathrm{l} / \mathrm{M}\right)$, and $1,842 \pm 449$ binding sites for $12 \mathrm{~F} 1$ $\left(K_{d}=1.5 \pm 0.2 \times 10^{-10}\right.$ liter $\left./ \mathrm{M}\right)$.

\section{Discussion}

We have detected glycoproteins antigenically related to VLA upon the surface of resting platelets confirming the observation of Hemler et al. (2) and proceeded to correlate these with previously studied platelet proteins. When analyzed by 1D SDS-PAGE, the VLA-2 specific antibody precipitated platelet molecules of two easily distinguishable sizes that, by size and 2D gel electrophoresis correspond with the component chains of the $\alpha^{2} \beta$ (VLA-2) heterodimer observed on activated T cells and other cell lines. Analysis of the VLA $\beta$-chain-specific mAb A-1 A5 precipitated platelet glycoproteins by $2 \mathrm{D}$ gels demonstrated 3 glycoproteins. The upper band corresponds to VLA $\alpha^{2}$ chain. The lower molecular weight band seen on ID SDSPAGE analysis is actually composed of two molecules, a heavily radioiodinated $145,000-M_{\mathrm{r}}$ chain with a $\mathrm{pI}$ of 4.7

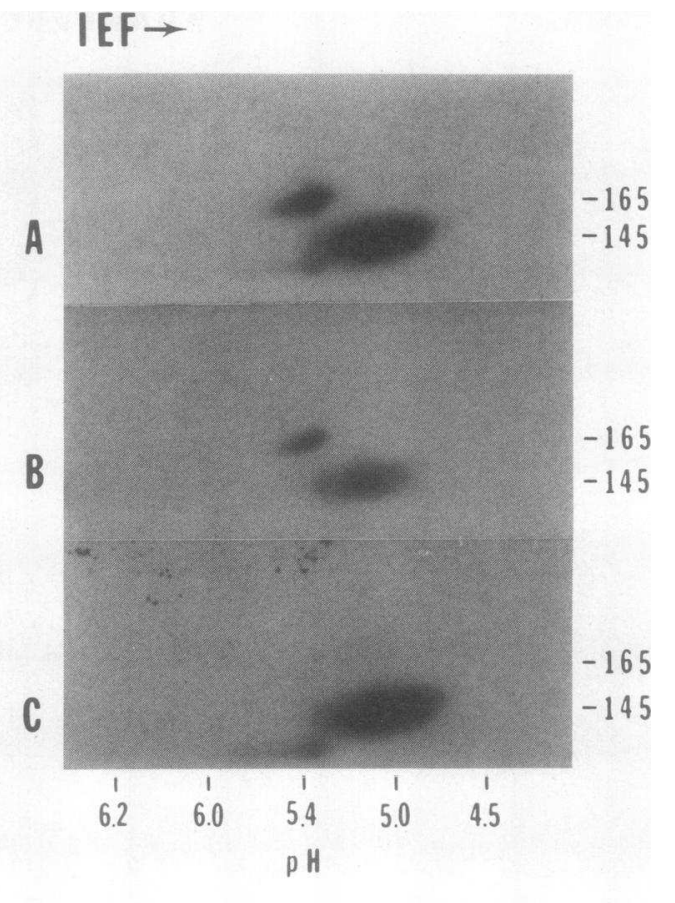

(lanes 3, 5, 7) and 2G12 (lanes 4 and 8). After 2-ME reduction the samples were run on $8 \%$ SDS-PAGE and autoradiographed. 2D electrophoresis was used to further analyse the content of the samples immunoprecipitated with A-1A5 (lane $1 A$ ), 12F1 (lane $5 B$ ) and A-1A5 of the $12 \mathrm{~F} 1$ depleted lysate (lane $6 C$ ).

that coelectrophoresed with T cell VLA $\beta$ chain and a weaker $140,000-M_{\mathrm{r}}$ component with a $\mathrm{pl}$ of 5.1 that may be hidden by the larger chain on 1D SDS-PAGE. This chain's pattern on 2D O'Farrell gels is similar to the VLA $\alpha^{3}$ or $\alpha^{5}$ chains. However it has been reported that the VLA-3 specific mAb J143 does not react with platelets (5), indicating it is unlikely GPIc is the VLA $\alpha^{3}$ chain.

The correlation of immunoprecipitation patterns and the apparent identity of the T cell VLA chains with the corresponding platelet proteins suggests strongly that these $\mathrm{mAb}$ retain their proven specificities $(1,5,8)$ in reacting with the platelet glycoproteins. Detailed study has shown that the A-1 A5 mAb reacts with the VLA $\beta$ chain and not with isolated $\alpha^{2}$ or $\alpha^{3}$ chains (5). Thus, we believe the mAb A-1A5 reacts specifically with the $145,000-M_{\mathrm{r}}$ chain and that the mAb $12 \mathrm{~F} 1$ reacts specifically with the $160,000-M_{\mathrm{r}}$ chain. Although experiments with dissociated platelet proteins have not been performed, their identical 2D electrophoresis patterns strongly support this conclusion.

Comparison of the positions of the three platelet molecules precipitated by VLA mAb A-1 A5 by two techniques, O'Farrell 2D gel and nonreduced-reduced SDS-PAGE gels, with the positions of previously named platelet glycoproteins has enabled us to identify them. The platelet protein corresponding to VLA $\alpha^{2}$ is the same as platelet GPIa. Platelet glycoprotein corresponding to VLA $\beta$ is the same as GPIIa. The platelet GPIc corresponds to a different VLA $\alpha$ chain, most likely VLA-5.

It is likely that these platelet molecules combine to form two mixed heterodimers, although more complex models such 
A

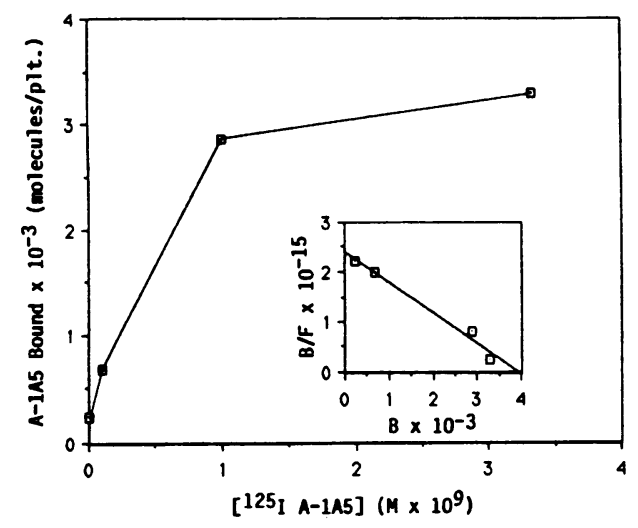

B

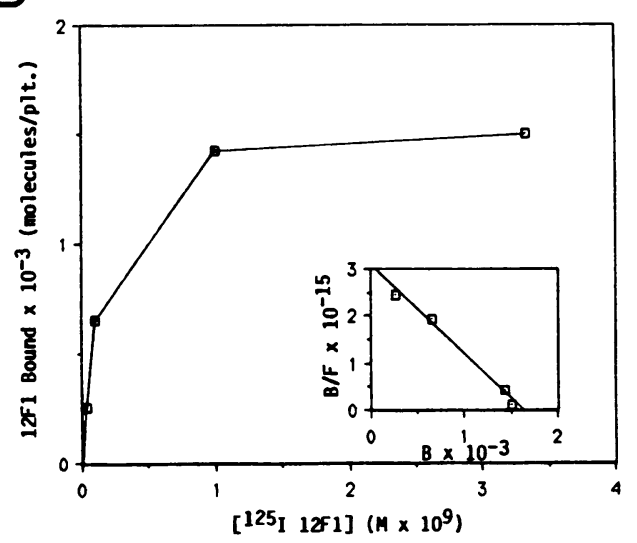

Figure 7. Binding of ${ }^{125} \mathrm{I}-\mathrm{A} 1 \mathrm{~A} 5$ and ${ }^{125} \mathrm{I}-12 \mathrm{~F} 1$ to resting platelets. Gel filtered platelets $\left(1 \times 10^{7} / \mathrm{ml}\right)$ from four normal male donors were suspended in modified Tyrode's buffer, $\mathrm{pH} 7.2$, containing TBG, 1 $\mathrm{mM} \mathrm{CaCl} 2$, and $1 \mu \mathrm{M} \mathrm{PGE}_{1}$. The platelets were reacted with, $(A)$ dilutions of radioiodinated DEAE-cellulose purified mAb A-1 A5 (3.33 $\left.\times 10^{-11}-1 \times 10^{-8} \mathrm{M}\right)$ or, $(B)$ dilutions of radioiodinated DEAE-cellulose purified $\mathrm{mAb} 12 \mathrm{~F} 1\left(3.33 \times 10^{-11}-1 \times 10^{-8} \mathrm{M}\right)$ for $60 \mathrm{~min}$ at $22^{\circ} \mathrm{C}$. Cell bound ligand was separated from free ligand by centrifugation of the platelet through $20 \%$ sucrose-TBG. Radioactivity was quantitated and the amounts of bound and free ligand calculated by reference to the specific activity of the radioiodinated antibodies. The results were analyzed by the method of Scatchard (27). Data from a representative study using platelets from a single donor are shown. Points represent the mean of triplicate determinations. In all cases the standard deviation from the mean were $<5 \%$ of the mean.

as a trimer that loses the Ic fragment upon $12 \mathrm{~F} 1$ binding have not been absolutely excluded. The VLA-2 specific mAb $12 \mathrm{~F} 1$ that is believed to react with GPII, immunoprecipitated both GPIa and GPIIa, indicating they form one type of heterodimer. A second heterodimer composed of GPIIa and GPIc was immunoprecipitated by the GPIIa reactive mAb A-1A5 after $12 \mathrm{~F} 1$ preclearance. The complex consisting of GPIIa associated with GPIa is believed to be analogous to the lymphocyte VLA-2 dimer and the proposed dimer GPIIa with GPIc analogous to VLA-3 or VLA-5 dimer. We think it unlikely that A-1 A5 immunoprecipitates the Ia and Ic chains as a result of their being variant molecules of Ila because numerous physical parameters including peptide mapping indicate that VLA $\alpha$ chain molecules are quite distinct from the VLA $\beta$-chain (4). That has also been shown for Ia and IIa (29). Testing of the VLA $\beta$-specific A-1A5 and heteroantisera to VLA- $\beta$ have shown no associated antigenic epitopes on $\alpha$ chains $(4,6)$. Evidence for each dimer has been found by immunoprecipitation and corroborative physical isolation of dimers is under investigation. The estimated number of surface GPIIa molecules (4926/platelet) is higher than the number of GPIa molecules (1842/platelet). This is consistent with $\sim 40 \%$ of the GPIIa forming a heterodimer with GPIa and the remainder of GPIIa forming dimers with GPIc. The amount of GPIIa and GPIa is at least an order of magnitude less than the amount of the other known adhesion receptor superfamily member present on platelets GPIIb/IIIa.

The existence of GPIIa-GPIc heterodimers in detergent solution has not been previously demonstrated, but a GPIIaGPIa association has been described by Kunicki et al. (30) who observed that GPIIa and GPIa are associated under conditions used for crossed immunoelectrophoresis. Whether the GPIIaIa complex occurs physiologically on intact platelets or if it exists only in detergent extracts of platelet membranes is not clear (31). Gogstad et al. showed that GPIIa and GPIa could be found in different crossed immunoelectrophoresis fractions (32). Our results confirm the association of GPIa and GPIIa in nonionic detergent extracts and may explain why only a fraction of GPIIa is associated with GPIa. Since those glycoproteins did not form complexes nonspecifically with other platelet membrane molecules, it is likely that the GPIa-IIa heterodimers are due to physiologically relevant complex associations present within the platelet membrane. That is supported by the cross-linking experiments of Davies and Palek (33) that indicate an association of GPIIa and GPIa on intact platelets. Chemical cross-linking experiments of membrane labeled $T$ cell lysates have also shown that VLA- 2 and VLA-3 are heterodimers and not homodimers $(4,5,8)$. Altogether these findings strongly suggest that the platelet GPIIa-GPIa and GPIIa-GPIc molecules exist as heterodimers prior to detergent lysis.

The identification of the platelet molecule analogous to the T cell VLA $\beta$ chain as GPIIa is based upon its location on 2D SDS-PAGE $\left(145,000 M_{\mathrm{r}}\right.$ and $\mathrm{pI}$ of 4.7$)$ and shared reactivity with mAb A-1A5. Similar to the $145,000 M_{\mathrm{r}}$ VLA $\beta$-chain. GMP-140 has a $140,000 \mathrm{~mol}$ wt and a pI of $4.4(22,34)$ and is probably identical with the platelet activation-dependent granule-external membrane (PADGEM) protein $(35,36)$. MAb S12 was originally thought to bind to GPIIa (19) but now has clearly been shown to bind to GMP-140. Other antibodies to platelet membrane antigens have been identified that react with molecules having similar electrophoretic properties, including glycoproteins G4 and G8 (32), GP 4-4.5 (29, 37), and the molecules described by Spycher et al. (38). The platelet granule protein GMP-140 recognized by $\mathrm{mAb} S 12(22,34)$ and by a mAb KC $4(35,36)$ has similar electrophoretic properties as the VLA $\beta$-chain but direct comparison clearly distinguishes each from the other (Fig. 3).

The recognition that platelet molecules structurally similar or identical to VLA are composed of the platelet components GPIIa, GPIa, and GPIc is significant in that it relates two previously separate fields of study. Previous and future findings of each field may be applicable to the other. For example the gene coding for the VLA $\beta$-chain has been mapped to human chromosome 10 and the VLA $\alpha^{2}$ gene is located on a different chromosome (39). If the indistinguishable chains are in fact identical, the GPIIa and GPIa genes should have the same locations and sequences as their counterparts. Other predictions also follow, including the associated GPIa-GPIIa 
molecules should be dissociated by treatment with high $\mathrm{pH}$ as has been observed with VLA-2 (4) and the amino acid sequences of the VLA $\alpha^{2}(40)$ and the VLA $\beta$-chains should apply to GPIa and GPIIa. Also, VLA $\alpha^{2}$ should bind $\mathrm{CA}^{2+}$ as GPIa does (41).

GPIa, GPIIa, and GPIc constitute three of the six most prominent iodinated surface glycoproteins on platelets; thus they may serve a number of important functions. Little is known of their physiological role, but given the relatedness of VLA to receptors for adhesion molecules one likely possibility is that they contribute to the triggering and adhesion events of platelets. Two of the other three prominent platelet membrane glycoproteins include the heterodimer, GPIIb-GPIIIa, which recognizes an Arg-Gly-Asp (R-G-D) sequence of fibrinogen $(42,43)$, fibronectin $(44,45)$, von Willebrand factor $(46,47)$, and vitronectin (48). By analogy, the GPIIa-GPIa and GPIIaGPIc complexes may also serve receptor functions important in platelet activation or adherence, and the VLA heterodimers on other cell types may have similar roles. Possible ligands are suggested by the recent reports that platelets from a patient lacking GPIa was found to have defective adherence to human collagen type III (49); and that a platelet glycoprotein with an electrophoretic behavior similar to GPIa binds to collagen and that binding is inhibited by wheat germ agglutinin, a lectin that binds to GPIa (50). Thus, the GPIa-IIa dimer on platelets and by analogy VLA-2 on other cell types may be collagen receptors. Another recent study indicates that VLA-3 and VLA-5 proteins act like fibronectin/laminin receptors (6).

The recognition that platelet glycoproteins GPIIa, GPIa, and GPIc are related or identical to VLA should enhance analysis of their structure and function. MAbs specific to individual platelet VLA glycoproteins will enable the isolation of individual platelet proteins. A-1A5 reacts with the common $\beta$ chain of VLA (4), which is identical to platelet GPIIa, and $12 \mathrm{~F} 1$ binds specifically to the $\alpha^{2}$-chain of VLA (GPIa) (40). Other VLA-specific mAb also should be useful, including the mAb J143 (51) recently shown to react with VLA-3, which may react specifically with GPIc. These VLA specific mAbs to cell surface receptors may prove to be useful probes of the physiologic role of GPIIa and GPIa in platelet activation and adherence.

Note added in proof. M. E. Hemler (personal communication) has recently found that platelets bear VLA-5 and a new form of VLA, VLA-6, but do not bear VLA-3. This suggests that GPIc corresponds to the VLA $\alpha^{5}$ or $\alpha^{6}$ chain.

\section{Acknowledgments}

We thank Esther Avery, Laura Wolff, and Laura Langman for valuable assistance in these experiments and Martin Hemler for helpful discussions.

These studies were supported in part by National Institutes of Health grants AM-30036, HL-30480, AM-07062, AI-24624, and CA-09174, and a grant from the University-Wide Task Force on AIDS. Dr. Pischel is the recipient of an Arthritis Foundation Investigator Award.

\section{References}

1. Hemler, M. E., C. F. Ware, and J. L. Strominger. 1983. Characterization of a novel differentiation antigen complex recognized by a monoclonal antibody (A-1A5): unique activation-specific molecular forms on stimulated T cells. J. Immunol. 131:334-340.
2. Hemler, M. E., F. Sanchez-Madrid, T. J. Flotte, A. M. Krensky, S. J. Burakoff, A. K. Bhan, T. A. Springer, and J. L. Strominger. 1984. Glycoproteins of 210,000 and 130,000, M.W. on activated T cells: Cell distribution and antigenic relation to components on resting cells and T cell lines. J. Immunol. 132:3011-3018.

3. Hemler, M. E., J. G. Jacobson, M. B. Brenner, D. Mann, and J. S. Strominger. 1985. VLA-1: a T cell surface antigen which defines a novel late stage of human T cell activation. Eur. J. Immunol. 15:502508.

4. Hemler, M. E., J. G. Jacobson, and J. L. Strominger. 1986. Biochemical characterization of VLA-1 and VLA-2: Cell surface heterodimers on activated T cells. J. Biol. Chem. 260:15246-15252.

5. Hemler, M. E., C. Huang, and L. Schwarz. 1987. The VLA protein family: Characterization of five distinct cell surface heterodimers each with a common $130,000 \mathrm{M}_{\mathrm{r}}$ beta subunit. J. Biol. Chem. 262:3330-3309.

6. Takada, Y., C. Huang, and M. E. Hemler. 1987. Fibronectin receptor structures in the VLA family of heterodimers. Nature 326:607-609.

7. Hynes, R. O. 1987. Integrins. A family of cell surface receptors. J. Cell. 48:549-554.

8. Pischel, K. D., M. E. Hemler, C. Huang, H. G. Bluestein, and V. L. Woods, Jr. 1987. Use of the monoclonal antibody $12 \mathrm{~F} 1$ to characterize the differentiation antigen VLA-2. J. Immunol. 138:226233.

9. Clemetson, K. J., A. Capitanio, and E. F. Lüscher. 1979. High resolution two-dimensional electrophoresis of the proteins and glycoproteins of human blood platelets and platelet membranes. Biochim. Biophys. Acta. 553:11-24.

10. Sixma, J. J., and M. E. Schiphorst. 1980. Identification of ectoproteins of human platelets. Combination of radioactive labelling and two-dimensional electrophoresis. Biochim. Biophys. Acta. 603:70-83.

11. McGregor, J. L., K. J. Clemetson, E. James, A. Capitanio, T. Greenland, E. F. Lüscher, and M. Dechavanne. 1981. Glycoproteins of platelet membranes from Glanzmann's thrombasthenia. A comparison with normal using carbohydrate or protein-specific labelling techniques and high-resolution, two dimensional gel electrophoresis. Eur. J. Biochem. 116:379-388.

12. Nurden, A. T., D. Dupuis, T. J. Kunicki, and J. P. Caen. 1981. Analysis of the glycoprotein and protein composition of Bernard-Soulier platelets by single and two-dimensional sodium dodecyl sulfate polyacrylamide gel electrophoresis. J. Clin. Invest. 67:1431-1440.

13. Phillips, D. R., and P. P. Agin. 1977. Platelet plasma membrane glycoproteins. Evidence for the presence of nonequivalent disulfide bonds using nonreduced-reduced two-dimensional gel electrophoresis. J. Biol. Chem. 252:2121-2126.

14. Boyum, A. 1968. Separation of lymphocytes from blood and bone marrow. Scand. J. Clin. Lab. Invest. 21(Suppl.): 77.

15. Julius, M. H., E. Simpson, and L. A. Herzenberg. 1973. A rapid method for the isolation of functional thymus-derived murine lymphocytes. Eur. J. Immunol. 3:645-649.

16. Saxon, A., R. H. Stevens, S. G. Quan, and D. W. Golde. 1978. Immunologic characterization of hairy cell leukemias in continuous culture. J. Immunol. 120:777-782.

17. Biedler, J. L., L. Helson, and B. A. Spengler. 1973. Morphology and growth, tumorigenicity, and cytogenetics of human neuroblastoma cells in continuous culture. Cancer Res. 33:2643-2652.

18. Bluestein, H. G. 1978. Neurocytoxic antibodies in serum of patients with systemic lupus erythematosus. Proc. Natl. Acad. Sci. USA. 75:3965-3639.

19. Woods, V. L., Jr., E. H. Oh, D. Mason, and R. McMillan. 1984. Autoantibodies against the platelet glycoprotein IIb/IIIa complex in patients with chronic ITP. Blood. 63:368-375.

20. Baur, S., E. S. Vitetta, C. J. Sher, I. Schendein, and J. W. Uhr. 1971. Isolation of heavy and light chains of immunoglobulin from the surfaces of lymphoid cells. J. Immunol. 106:1133-1135.

21. McMichael, A. J., N. A. Rust, J. R. Pilch, R. Sochynsky, J. 
Morton, D. Y. Mason, C. Ruan, G. Tobelem, and J. Caen. 1981. Monoclonal antibody to human platelet glycoproteins I. Haematology. 49:501-509.

22. McEver, R. P., and M. N. Martin. 1984. A monoclonal antibody to a membrane glycoprotein binds only to activated platetlets. $J$. Biol. Chem. 259:9799-9804.

23. Pischel, K. D., H. G. Bluestein, and V. L. Woods, Jr. 1986. Very late activation antigens are human leukocyte-neuronal crossreactive cell surface antigens. J. Exp. Med. 164:393-406.

24. Pischel, K. D., and J. R. Little. 1979. Shared chemical properties of different murine thymus-leukemia antigens. J. Immunol. 122:1821-1827.

25. Laemmli, U. K. 1970. Cleavage of structural proteins during the assembly of the head of bacteriophage T4. Nature (Lond.). 227:680-685.

26. Woods, V. L., Jr., L. E. Wolff, and D. M. Keller. 1987. Resting platelets contain a substantial centrally located pool of glycoprotein IIb-IIIa complex which may be accessible to some but not other extracellular proteins. J. Biol. Chem. 261:15242-15251.

27. Scatchard, G. 1949. The attractions of proteins for small molecules and ions. Ann. NY Acad. Sci. 51:660-672.

28. O'Farrell, P. H. 1975. High resolution two-dimensional electrophoresis of proteins. J. Biol. Chem. 250:4007-4021.

29. McGregor, J. L., K. J. Clemetson, E. James, P. Clezardin, M. Dechavanne, and E. F. Lüscher. 1982. Tryptic peptide map analysis of the major human blood platelet membrane glycoproteins separated by two-dimensional polyacrylamide gel electrophoresis. Biochim. Biophys. Acta. 689:513-522.

30. Kunicki, T. J., A. T. Nurden, D. Pidard, N. R. Russell, and J. P. Caen. 1981. Characterization of human platelet glycoprotein antigens giving rise to individual immunoprecipitates in crossed-immunoelectrophoresis. Blood. 58:1190-1197.

31. Kunicki, T. J. 1985. Organization of glycoproteins within the platelet plasma membrane. In Platelet Membrane Glycoproteins. J. N. George, A. T. Nurden, and D. R. Phillips, editors. Plenum Press, New York. 87-104.

32. Gogstad, G. O., M. B. Krutnes, O. Hetland, and N. O. Solum. 1983. Comparison of protein and lipid composition of the human platelet-granule membranes and glycerol lysis membranes. Biochim. Biophys. Acta. 732:519-530.

33. Davies, G. E., and J. Palek. 1982. Platelet protein organization. Analysis by treatment with membrane-permeable cross-linking reagents. Blood. 59:502-513.

34. Stenberg, P. E., R. P. McEver, M. A. Shuman, V. V. Jacques, and D. F. Bainton. 1985. A platelet alpha-granule membrane protein expressed on the plasma membrane after activation. J. Cell Biol. 101:880-886.

35. Hsu-Lin, S., C. L. Berman, B. F. Furie, D. August, and B. Furie. 1984. A platelet membrane protein expressed during platelet activation and secretion. J. Biol. Chem. 259:9121-9126.

36. Berman, C. L., E. L. Yeo, J. D. Wencel-Drake, B. C. Furie, M. H. Ginsberg, and B. Furie. 1986. A platelet alpha granule membrane protein that is associated with the plasma membrane after activation. J. Clin. Invest. 78:130-137.

37. McGregor, J. L., J. Brochier, F. Wild, G. Follea, M. C. Trze- ciak, E. James, M. Dechavanne, L. McGregor, and K. J. Clemetson. 1983. Monoclonal antibodies against platelet membrane glycoproteins: Characterization and effect on platelet function. Eur. J. Biochem. 131:427-436.

38. Spycher, M. O., K. J. Clemetson, and E. F. Lüscher. 1982. Surface labeling of human platelets by reductive methylation. Thromb. Haemostasis. 48:169-172.

39. Peters, P. M., M. E. Kamarck, M. E. Hemler, J. L. Strominger, and F. H. Ruddle. 1984. Genetic and Biochemical characterization of human lymphocyte cell surface antigens. The A-1 A5 and A-3A4 determinants. J. Exp. Med. 159:1441-1454.

40. Takada, Y., J. L. Strominger, and M. E. Hemler. 1987. The very late antigen family of heterodimers is part of a superfamily of molecules involved in adhesion and embryogenesis. Proc. Natl. Acad. Sci. USA. 84:3239-3243.

41. Gogstad, G. O., M. B. Krutues, and N. O. Sohum. 1983. Calcium-binding proteins from human platelets. A study using crossed immunoelectrophoresis and ${ }^{45} \mathrm{Ca}^{2+}$. Eur. J. Biochem. 133:193-199.

42. Bennett, J. S., J. A. Hoxie, S. F. Lettman, G. Vilaire, and D. B. Chines. 1983. Inhibition of fibrinogen binding to stimulated human platelets by a monoclonal antibody. Proc. Natl. Acad. Sci. USA. 80:2417-2421.

43. Marguerie, G. A., N. Thomas-Maison, M. H. Ginsberg, and E. F. Plow. 1984. The platelet-fibrinogen interaction. Evidence for proximity of the A alpha chain of fibrinogen to platelet membrane glycoproteins IIb/IIIa. Eur. J. Biochem. 139:5-11.

44. Gardner, J. M., and R. O. Hynes. 1985. Interaction of fibronectin with its receptor on platelets. Cell. 42:439-448.

45. Plow, E. F., R. P. McEver, B. S. Coller, V. L. Woods, Jr., and G. A. Marguerie. 1985. Related binding mechanisms for fibrinogen, fibronectin, von Willibrand factor, and thrombospondin on thrombin-stimulated human platelets. Blood. 66:724-727.

46. Ruggeri, Z. M., R. Bader, and L. DeMarco. 1982. Glanzmann's thrombasthenia: deficient binding of von Willebrand factor to thrombin-stimulated platelets. Proc. Natl. Acad. Sci. USA. 79:6038-6041.

47. Plow, E. F., M. D. Pierschbacher, E. Ruoslahti, G. A. Marguerie, and M. H. Ginsberg. 1985. The effect of arg-gly-asp-containing peptides on fibrinogen and von Willebrand factor binding to platelets. Proc. Natl. Acad. Sci. USA. 82:8057-8061.

48. Pytela, R., M. D. Pierschbacher, M. H. Ginsberg, E. F. Plow, and E. Ruoslahti. 1986. Platelet membrane glycoprotein IIb/IIIa: Member of a family of arg-gly-asp-specific adhesion receptors. Science (Wash. DC). 231:1559-1562.

49. Nieuwenhuis, H. K., K. S. Sakariassen, W. P. Houdijk, P. F. E. M. Nievelstein, and J. J. Sixma. 1986. Deficiency of platelet membrane glycoprotein Ia associated with a decreased platelet adhesion to subendothelium. A defect in platelet spreading. Blood. 68:692-695.

50. Santaro, S. A. 1986 . Identification of a 160,000 dalton platelet membrane protein that mediates the initial divalent cation-dependent adhesion of platelets to collagen. Cell. 46:913-920.

51. Fradet, Y., C. Cordon-Cardo, T. Thomason, M. E. Daly, W. F. Whitmore, K. O. Lloyd, M. R. Melamed, and L. L. Old. 1984. Cell surface antigens of human bladder cancer defined by mouse monoclonal antibodies. Proc. Natl. Acad. Sci. USA. 81:224-228. 